\title{
Applicability of continuous glucose monitoring to screen for cystic fibrosis-related diabetes onset and clinical impairment
}

\author{
Mariana Zorron ${ }^{1}$, Fernando Marson ${ }^{2}$, André Morcillo ${ }^{1}$, Aline Gonçalves ${ }^{1}$, Mayra de Souza \\ El Beck ${ }^{1}$, Jose Ribeiro ${ }^{1}$, and Antônio Ribeiro ${ }^{1}$ \\ ${ }^{1}$ State University of Campinas Faculty of Medical Sciences \\ ${ }^{2}$ Universidade São Francisco
}

June 26, 2021

\begin{abstract}
Background and Objectives: Cystic fibrosis-related diabetes is the major comorbidity in cystic fibrosis and reduces life expectancy, highlighting the need for early diagnosis and treatment. This study aimed to verify whether abnormal continuous glucose monitoring results predict cystic fibrosis-related diabetes onset and/or a decline in the forced expiratory volume in the 1st second or body mass index of patients with cystic fibrosis. Methods: Thirty-nine patients with cystic fibrosis (age 10-19 years) were screened for cystic fibrosis-related diabetes using the oral glucose tolerance test. Patients without diabetes diagnose underwent 3 days of continuous glucose monitoring, spirometry and body mass index measurements and were reassessed at the end of the study with a second spirometry, body mass index evaluation and oral glucose tolerance test. Results: Thirty-four patients completed the follow-up ( $3.1 \pm 0.51$ years). None of the study variables predicted cystic fibrosis-related diabetes progression or were associated with hypoglycemic events. Continuous glucose monitoring could detect glucose abnormalities not revealed in the oral glucose tolerance test. Patients with glucose level of $>140 \mathrm{mg} / \mathrm{dL}$ on continuous glucose monitoring showed significantly lower body mass index z scores at both study initiation $(-1.55 \pm 1.68$ vs. $-0.17 \pm 0.88$; p-value $=0.02)$ and completion $(-1.65 \pm 1.55$ vs. $-0.42 \pm 1.08$; p-value $=0.039)$. Conclusions: Continuous glucose monitoring can identify glucose abnormalities not detected by oral glucose tolerance test that are related to early stage decreases in body mass index. However, it was ineffective in predicting the onset of diabetes in this cystic fibrosis population. Different diagnostic criteria for diabetes may be required for individuals with cystic fibrosis.
\end{abstract}

\section{Hosted file}

Main_manuscript_Pediatric_pulmonology_oficial.docx available at https://authorea.com/users/ 422180/articles/527922-applicability-of-continuous-glucose-monitoring-to-screen-forcystic-fibrosis-related-diabetes-onset-and-clinical-impairment

\section{Hosted file}

Tables_pediatric_pulmonology.docx available at https://authorea.com/users/422180/articles/ 527922-applicability-of-continuous-glucose-monitoring-to-screen-for-cystic-fibrosisrelated-diabetes-onset-and-clinical-impairment 
Figure 1

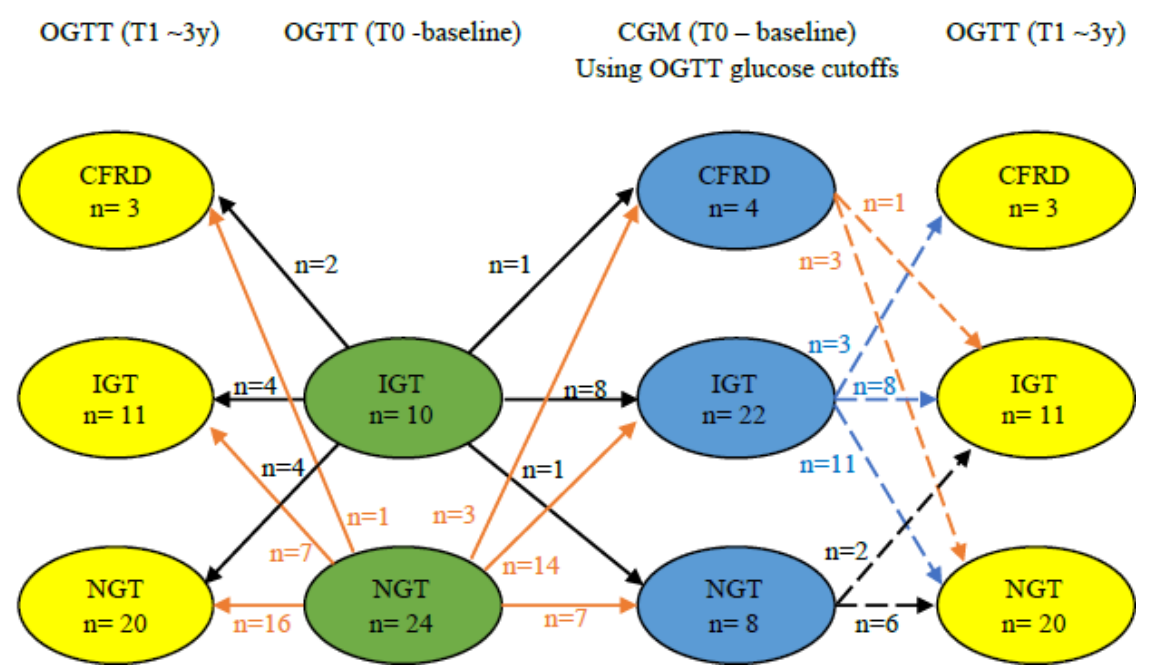

